\title{
Cerebrovascular Mechanisms in Perinatal Asphyxia: The Role of Vasogenic Brain Edema
}

\author{
W. A. TWEED, ${ }^{(15)}$ MICHAEL PASH, AND GEORGE DOIG
}

\begin{abstract}
Summary
Previous studies from our laboratory have demonstrated penetration of Evan's blue dye into the brain in profound fetal asphyxia, suggesting that vasogenic brain edema (BE) might be an immediate contributing factor in asphyxial brain injury. We modified the ${ }^{125}$ Ilabeled albumin method of Pappius and McCann to quantitate vasogenic BE after acute fetal asphyxia. With ${ }^{51} \mathrm{Cr}$-labeled red cells to measure intravascular volume, and ${ }^{125}$ I-labeled albumin to measure total tissue plasma, the equivalent extra vascular plasma volume, i.e., vasogenic BE, was calculated. Twenty chronically prepared animals were studied, six nonasphyxiated controls and 14 asphyxiated (of which six term animals were normotensive and five term and three premature animals were hypertensive during asphyxia). No difference in extra vascular plasma volume was found between asphyxiated and control animals in any of four brain regions. We conclude that, although blood brain barrier function might be impaired, vasogenic $B E$ is not quantitatively significant immediately after severe fetal asphyxia.
\end{abstract}

\section{Speculation}

An episode of acute, profound asphyxia in the fetal lamb is not accompanied by the formation of measurable amounts of vasogenic brain edema. Therefore, brain swelling is probably not an important factor in the genesis of acute hypoxic neurologic injury.

This study is part of our ongoing investigations of cerebrovascular mechanisms in asphyxial brain injury of the newborn using a fetal sheep model. Previous studies from our laboratory have demonstrated that Evan's blue dye penetrates the blood brain barrier (BBB) of the fetus during severe asphyxia (5), particularly with a fluctuating fetal blood pressure. Impairment of the BBB might lead to the formation of vasogenic brain edema (BE), a possible contributing factor in asphyxial brain injury. The present study was designed to quantitate the amount of vasogenic $B E$ formed during an acute asphyxial insult. Preliminary to this study, we developed and validated a method to quantitate vasogenic $\mathrm{BE}$ applicable to in utero fetal studies (8).

\section{MATERIALS AND METHODS}

Acute vasogenic $B E$ is nearly equivalent in composition to serum (3), so that ${ }^{125}$ I-labeled albumin (RISA) can be used as a measure of vasogenic BE formation. The RISA method we used is based on that of Pappius and McCann (7), but a modification to correct for regional intravascular plasma volume increases its precision for regional BE determination (8). By using two labels, ${ }^{25} \mathrm{I}$ albumin and ${ }^{51} \mathrm{Cr}$-labeled red blood cells, total tissue albumin, intravascular plasma volume and the equivalent extravascular plasma volume (EVPV), equivalent to vasogenic $B E$, can be calculated.

$$
\begin{aligned}
& \text { EVPV }=\frac{{ }^{125} \mathrm{I} \text { counts } / \mathrm{g} \text { tissue }}{{ }^{125} \mathrm{I} \text { counts } / \mathrm{ml} \text { plasma }} \\
& -\left[\frac{{ }^{51} \mathrm{Cr} \text { counts } / \mathrm{g} \text { tissue }}{{ }^{51} \mathrm{Cr} \text { counts } / \mathrm{ml} \text { blood }} \times(1-\text { hematocrit })\right]
\end{aligned}
$$

EVPV in acute brain injury (with BBB disruption) has been shown to closely estimate excess tissue water measured gravimetrically (8).

Twenty animals were studied, six nonasphyxiated controls and 14 asphyxiated animals. The near-term pregnant ewe was prepared under spinal or halothane/oxygen general anesthesia. A small hysterotomy incision was made for insertion of fetal catheters: a femoral artery catheter for monitoring fetal blood pressure, heart rate, and arterial blood gases and a femoral venous catheter for injection of the isotopes. In asphyxial experiments, an inflatable occlusion loop was placed around the umbilical cord of the fetus (12). After inserting femoral arterial and venous catheters in the ewe, all catheters were brought to the surface, and the incisions were closed.

Studies were performed $24 \mathrm{hr}$ later after both fetus and ewe had recovered to stable cardiovascular and acid-base conditions. After control measurements were made, the isotopes were injected into the fetus, $6 \mu \mathrm{Ci}$ of RISA and $20 \mathrm{ml}$ of fetal blood tagged with 50 $\mu \mathrm{Ci}$ of ${ }^{51} \mathrm{Cr}$. One $\mathrm{hr}$ was then allowed for distribution of the isotopes.

The ${ }^{125}$ I-labeled RISA was obtained from Charles E. Frost Radiopharmaceuticals. Their quality control specifications allow not more than $0.5 \%$ unbound radio activity at preparation and not above $2 \%$ at the end of three half-lives. The ${ }^{51} \mathrm{Cr}$-tagged fetal red blood cells were washed with normal saline until the supernatant contained less than $1 \%$ unbound radioactivity.

\section{CONTROL NONASPHYXIATED STUDIES}

The animals were studied with the ewe lying quietly in a transport cart. Maternal and fetal blood pressure and heart rate were continuously recorded with a polygraph recorder, and arterial blood gases and acid base state were determined on each at regular intervals using a Corning 165 gas analyzer. Maternal rectal temperature was also recorded. Beginning one hr after isotope injection, fetal blood samples were withdrawn at half hourly intervals for determination of average isotope counts in whole blood and plasma. After $2 \mathrm{hr}$ of physiologic monitoring and $3 \mathrm{hr}$ after isotope injection, both fetus and ewe were painlessly killed by intravenous injections of $\mathrm{KCl}$ solution. The fetal brain was quickly removed, and bilateral 2 to $3 \mathrm{~g}$ samples from brainstem, cerebellum, deep cerebral ganglia, and cerebral hemispheres (three samples from each side) were placed in glass counting tubes, each packed to the same level, for counting in a gamma well counter.

Sampling included all of the brainstem tissue below the upper pontine border, all of the deep cerebral grey matter (the basal ganglia, diencephalon, and midbrain) and about $50 \%$ of the remaining cerebellar and cerebral hemispheric tissue.

\section{ASPHYXIA STUDIES}

Monitoring of the animals, isotope labeling, and handling of the specimens were identical to the controls.

One hr after isotope labeling, gradual progressive fetal asphyxia was induced by incrementably inflating the umbilical occlusion loop until a fetal pH of between 7.00 and 7.10 was reached, and this was maintained for 30 to $60 \mathrm{~min}$. This was generally accom- 
panied by sustained fetal bradycardia and a calculated (2) arterial $\mathrm{O}_{2}$ saturation always less than $20 \%$. The animals were sacrificed with $\mathrm{KCl}$, and the fetal brain was examined as described above.

\section{RESULTS}

Seventeen animals were near term (135 to 140 days) with fetal weights of 4 to $5 \mathrm{~kg}$; three premature animals (120 to 125 days) weighed 2.5 to $3.0 \mathrm{~kg}$. Maternal temperature was 38 to $39^{\circ} \mathrm{C}$ throughout.

The results are depicted in Tables 1 and 2 .
Maternal and fetal blood pressures, blood gases, and acid-base conditions for the control group and the preasphyxial and endasphyxial values of the asphyxiated group are illustrated in Table 1. After $24 \mathrm{hr}$ stabilization, at the onset of the study, these measures were identical in control and asphyxia groups.

During 1 to $2 \mathrm{hr}$ of partial umbilical cord compression, progressive asphyxia and acidosis developed, with fetal $\mathrm{pH}$ depressed to about 7.00 and arterial oxygen saturation always to less than $20 \%$ by the termination of the asphyxial experiments. Six of the mature asphyxiated fetuses maintained control levels of blood pressure, two became spontaneously hypertensive during asphyxia

Table 1. Maternal and fetal blood pressure, blood gases, and acid-base in nonasphyxia and asphyxia studies ${ }^{1}$

\begin{tabular}{|c|c|c|c|c|c|}
\hline & $\begin{array}{c}\text { Blood pressure } \\
\text { (mean) }\end{array}$ & $\mathrm{PaO}_{2}$ & $\mathrm{O}_{2}$ saturation & $\mathrm{PaCO}_{2}$ & $\mathrm{pHa}$ \\
\hline \multicolumn{6}{|c|}{ Nonasphyxiated control } \\
\hline Maternal & $91.0 \pm 10.8^{2}$ & $76.8 \pm 8.4$ & $97.0 \pm 5.6$ & $30.6 \pm 3.1$ & $7.54 \pm 0.05$ \\
\hline Fetal & $57.8 \pm 5.5$ & $15.8 \pm 3.3$ & $36.1 \pm 14.1$ & $43.7 \pm 6.0$ & $7.35 \pm 0.05$ \\
\hline \multicolumn{6}{|l|}{ Asphyxiated } \\
\hline Maternal & $91.5 \pm 11.6$ & $81.1 \pm 11.8$ & $97.2 \pm 12.4$ & $28.2 \pm 5.2$ & $7.51 \pm 0.05$ \\
\hline Fetal preasphyxia & $60.0 \pm 9.5$ & $15.7 \pm 2.8$ & $34.3 \pm 12.4$ & $39.4 \pm 5.2$ & $7.34 \pm 0.07$ \\
\hline End asphyxia & $64.6 \pm 18.1$ & $15.0 \pm 5.1$ & $13.3 \pm 10.1$ & $57.1 \pm 18.5$ & $6.97 \pm 0.11$ \\
\hline
\end{tabular}

${ }^{1}$ Arterial blood samples of all fetuses were from the femoral artery.

${ }^{2}$ Mean \pm S.E.

Table 2. Vasogenic brain edema as EVPV of ${ }^{125} \mathrm{I}$ in the fetal brain (ml/100 $\mathrm{g}$ tissue $)^{1}$

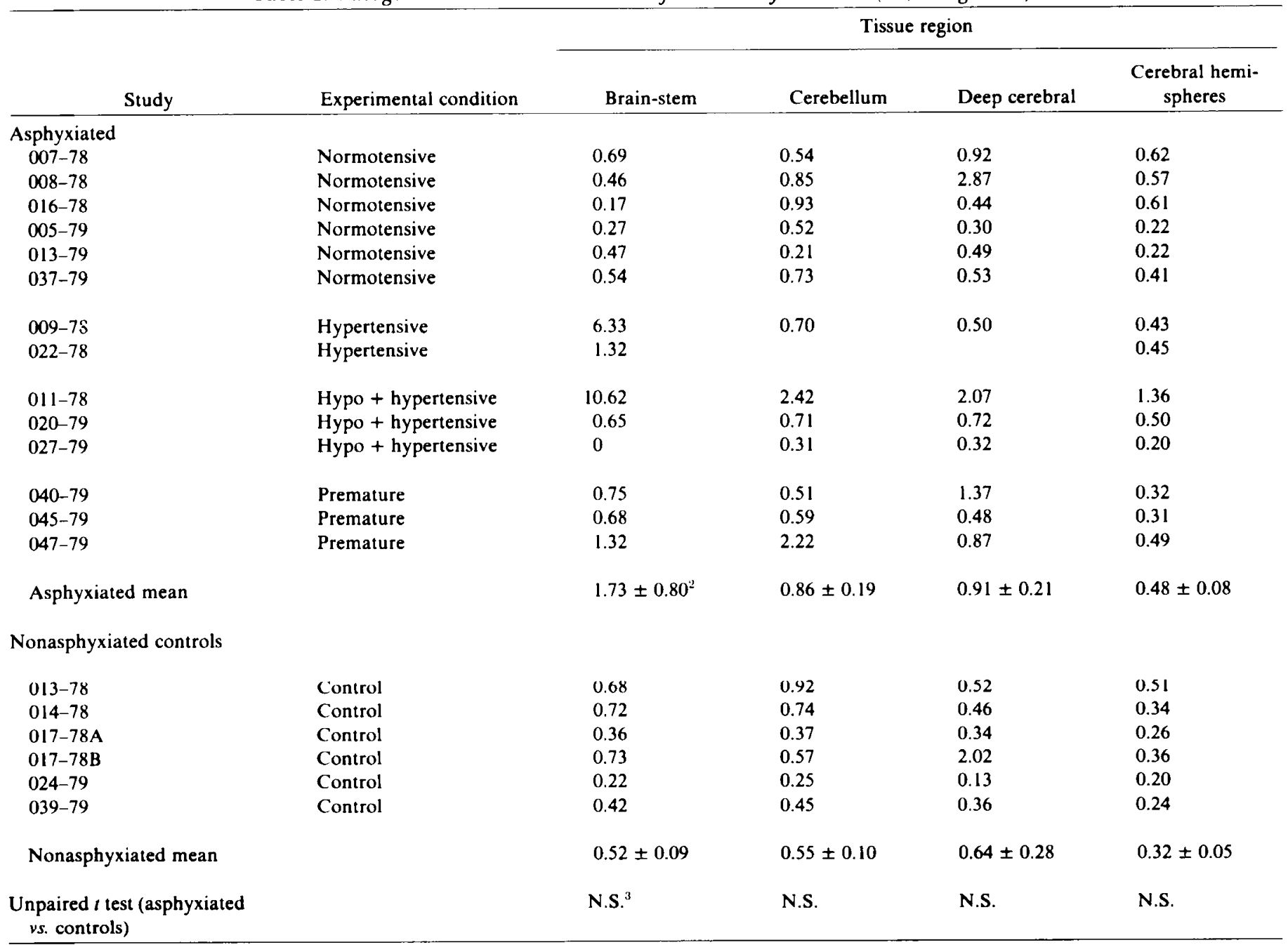

\footnotetext{
' Vasogenic brain edema was estimated as EVPV of ${ }^{125} \mathrm{I}$ in the fetal brain in $\mathrm{ml} / 100 \mathrm{~g}$ tissue. Tissue from four brain regions was examined. In none of these regions did the difference in EVPV between asphyxiated and control animals reach statistical significance.

${ }^{2}$ Mean \pm S.E.

${ }^{3}$ N.S.. not sienificant.
} 
(43 and $27 \%$ increase), and three were first deliberately made hypotensive by blood withdrawal with subsequent hypertension after reinfusion. The three premature animals all developed spontaneous hypertension (average increase, 27\%).

The equivalent EVPV in $\mathrm{ml} / 100 \mathrm{~g}$ of tissue was calculated for the four brain areas under consideration (Table 2). This amounted to about $0.5 \mathrm{ml} / 100 \mathrm{~g}$ of brain in the control group, equivalent to about $30 \%$ of the calculated intravascular plasma volume in these experiments. There was no striking difference between different areas of the brain in the nonasphyxiated animals except one in which greater ${ }^{125}$ I penetration occurred in the deep cerebral ganglia.

EVPV in asphyxia and control groups was compared by the unpaired $t$ test. The differences did not reach statistical significance $(P<0.05)$ in any of the four tissue regions. The actual differences in EVPV between the two groups was small, with an average excess of $0.16 \mathrm{ml}$ EVPV per $100 \mathrm{~g}$ of tissue in the cerebral hemispheres of asphyxiated animals.

There were no differences in excess EVPV in different groups of asphyxiated animals, normotensive, hypertensive, fluctuating hypertension, or premature animals.

\section{DISCUSSION}

After resting undisturbed for $24 \mathrm{hr}$ postoperatively, ewes and fetuses had stabilized with arterial $\mathrm{PO}_{2}, \mathrm{PCO}_{2}$, and $\mathrm{pH}$ values within the range of normal reported in the literature for femoral arterial blood (13), and with normal blood pressure and heart rate. Inasmuch as fetal oxygenation was at the lower end of normal, we must presume a mild degree of fetal stress in all animals as a result of uterine vasoconstriction from manipulation, surgery, and maternal catecholamine secretion. However, this would not affect the conclusions, because the two groups were identical.

Our method attempts to quantitate BBB function by estimating the penetration of albumin into the brain, calculated as the equivalent EVPV. The normal adult BBB is practically impermeable to albumin. Therefore, our calculation of approximately $0.5 \mathrm{ml} / 100 \mathrm{~g} \mathrm{EVPV}$ in control animals requires explanation. There are three factors that probably contribute to this. The first is extravascular penetration of small amounts of unbound ${ }^{125} \mathrm{I}$. Because the commercial RISA preparation contains not more than $0.5 \%$ unbound radioactivity when fresh and not more than $2 \%$ at the end of three half-lives, this is not a major factor. The second is the possibility that the immature BBB has different permeability characteristics than that of the adult. Saunders (9) has documented both an increase in the ratio of brain/plasma concentrations for albumin and increased penetration of labeled albumin into the brain in the very young fetus. With growth in utero, both of these approached adult values, and evidence suggests that the characteristics of the mature fetal BBB approximate those of the adult. The third and best supported explanation is that the hematocrit in the cerebral microcirculation is lower than that in large vessels. Sklar et al. (11) found that estimates of cerebral blood volume with RISA were significantly higher than those obtained with ${ }^{51} \mathrm{Cr}$ and attributed the major part of this difference is a lower hematocrit in cerebral vessels. Larson and Lassen (4), using arteriovenous dilution curves of RISA and ${ }^{51} \mathrm{Cr}$, estimated that in normal man the average cerebral hematocrit is $92.2 \%$ of the large vessel hematocrit. This error would cause us to underestimate cerebral intravascular plasma volume and overestimate EVPV, and our estimation of EVPV in control animals is approximately equal to the difference between RISA and ${ }^{51} \mathrm{Cr}$ cerebral blood volumes reported by Sklar et al. (11). However, the sources of error apply equally to both control and asphyxia animals.

The method assumes the equivalency of extravascular albumin and vasogenic BE. Previous validation experiments in our labo- ratory (8) have confirmed this in a different animal model. In acute experiments with BBB breakdown, i.e., a focal freeze lesion in the rabbit brain, calculation of vasogenic BE as EVPV corresponded very closely to the gravimetrically determined excess water in the tissue.

Although a severe asphyxial stress may impair the BBB in the fetus (5), the amount of vasogenic BE accumulated in the time span of these experiments was not impressive, less than $1 / 2 \%$ of wet tissue weight, and not statistically significant. There were no evident differences attributable to differences in blood pressure or maturity. Although the association between acute hypertension and $\mathrm{BBB}$ disruption has been well established (1), the present data cannot be used to confirm or exclude this mechanism in the fetus. Further studies aimed at more precise examination of BBB function are required.

Despite the lack of BE immediately after asphyxia, this does not allow us to predict the course of events if the fetus is successfully resuscitated from the asphyxial episode or if the asphyxia is more protracted. However, the study was designed specifically to examine acute edema formation as a possible immediate factor in asphyxial injury.

This study indicates that vasogenic BE formation is not quantitatively significant during acute profound fetal asphyxia and discounts the importance of BE in the genesis of acute fetal asphyxial brain injury. The pathologic demonstration by other authors of brain swelling immediately after asphyxia (6) more likely represents the consequences of cerebral infarction and necrosis (10) with intracellular (cytotoxic) edema accumulation.

\section{REFERENCES AND NOTES}

1. Haggendal, E., and Johansson, B.: On the pathophysiology of the increased cerebrovascular permeability in cute arterial hypertension in cats. Acta Neurol. Scand., 48: 265 (1972).

2. Hellegers, A. E., and Schruefer, J. J. P.: Nomograms and empirical equations relating oxygen tension, percentage saturation, and $\mathrm{pH}$ in maternal and fetal blood. Am. J. Obstet. Gynecol., 81: 377 (1961).

3. Katzman, R., and Pappius, H. M.: Brain electrolytes and fluid metabolism. pp. 336-408 (The Williams \& Wilkins Co., Baltimore, MD, 1973).

4. Larson, O. A., and Lassen, N. A.: Cerebral hematocrit in normal man. J. Appl. Physiol, 19: 571 (1964).

5. Lou, H. C., Lassen, N. A., Tweed, W. A. et al.: Pressure passive cerebral blood now and breakdown of the blood-brain barrier in experimental fetal asphyxia. Acta Paediatr. Scand., 68: 57 (1979).

6. Myers, R. E., Beard, R., and Adamsons, K.: Brain swelling in the newborn rhesus monkey following prolonged partial asphyxia. Neurology, 19: 1012 (1969).

7. Pappius, H. M., and McCann, W. P.: Effects of steroids on cerebral edema in cats. Arch. Neurol., 20: 207 (1969).

8. Pash, M. P., and Tweed, W. A.: Tissue albumin and water content in the early stages of vasogenic brain edema formation. Can. J. Neurol. Sci., 6: 423 (1979).

9. Saunders, N. R.: The blood brain barrier in the foetal and newborn lamb. Ann. Rech. Vet., 8: 384 (1977).

10. Selzer, M. E., Myers, R. E., and Halstein, S. B.: Prolonged partial asphyxia: effects on fetal brain water and electrolytes. Neurology, 22: 732 (1972).

11. Sklar, F. H., Burke, E. F., Jr., and Langfitt, T. W.: Cerebral blood volume: values obtained with $\mathrm{Cr}^{\mathrm{s}}$ labelled red blood cells and RISA. J. Appl. Physiol., 24: 79 (1968).

12. Towell, M. E., and Salvador, H. S.: Compression of the umbilical cord: An experimental model in the fetal goat. In: P. G. Crosignani, G. Pardi: Fetal Evaluation During Pregnancy and Labour. pp. 143-156 (Academic Press, Inc. New York, 1971).

13. Vannucci, R. C., and Plum, F.: Pathophysiology of perinatal hypoxicischemic brain damage. In: G. E. Gaull: Biology of Brain Dysfunction. Vol. 3 (Plenum Press, New York, 1975).

14. The technical assistance of Miss Maureen Cumming and Mr. Wayne Pucci is gratefully acknowledged.

15. Requests for reprints should be addressed to: W. A. Tweed, M.D., F.R.C.P.(C), Department of Anesthesia, Faculty of Medicine. The University of Manitoba, Winnipeg, Manitoba, Canada R3E 0W3.

16. This research was supported by the Medical Research Council of Canada and the Manitoba Heart Foundation.

17. Received for publication January 17, 1980

18. Accepted for publication July 1, 1980. 